\title{
Report on 240Am(n,x) surrogate cross section test measurement
}

J. J. Ressler, J. T. Burke, J. Gostic, D. Bleuel, J. E. Escher, R. A. Henderson, J. Koglin, T. Reed, N. D. Scielzo, M. A. Stoyer

February 2, 2012 
This document was prepared as an account of work sponsored by an agency of the United States government. Neither the United States government nor Lawrence Livermore National Security, LLC, nor any of their employees makes any warranty, expressed or implied, or assumes any legal liability or responsibility for the accuracy, completeness, or usefulness of any information, apparatus, product, or process disclosed, or represents that its use would not infringe privately owned rights. Reference herein to any specific commercial product, process, or service by trade name, trademark, manufacturer, or otherwise does not necessarily constitute or imply its endorsement, recommendation, or favoring by the United States government or Lawrence Livermore National Security, LLC. The views and opinions of authors expressed herein do not necessarily state or reflect those of the United States government or Lawrence Livermore National Security, LLC, and shall not be used for advertising or product endorsement purposes.

This work performed under the auspices of the U.S. Department of Energy by Lawrence Livermore National Laboratory under Contract DE-AC52-07NA27344. 


\section{Report on ${ }^{240} \mathrm{Am}(\mathrm{n}, \mathrm{x})$ surrogate cross section test measurement}

J.J. Ressler. J.T. Burke, J. Gostic, D. Bleuel, J.E. Escher, R.A. Henderson, J. Koglin, T.

Reed, N.D. Scielzo, M.A. Stoyer

\section{Objective}

The main goal of the test measurement was to determine the feasibility of the ${ }^{243} \mathrm{Am}(\mathrm{p}, \mathrm{t})$ reaction as a surrogate for ${ }^{240} \mathrm{Am}(\mathrm{n}, \mathrm{f})$. No data cross section data exists for neutron induced reactions on ${ }^{240} \mathrm{Am}$; the half-life of this isotope is only 2.1 days making direct measurements difficult, if not impossible.

The 48-hour experiment was conducted using the STARS/LIBERACE experimental facility located at the 88 Inch Cyclotron at Lawrence Berkeley National Laboratory in August 2011. A description of the experiment and results follow.

\section{Design of experiment}

Similar to other actinide surrogate reactions under this project, data from two reactions were collected. The surrogate reactions used in the test experiment were ${ }^{243} \mathrm{Am}(\mathrm{p}, \mathrm{t})$ and ${ }^{238} \mathrm{U}(\mathrm{p}, \mathrm{t})$ which are surrogates for ${ }^{240} \mathrm{Am}(\mathrm{n}, \mathrm{x})$ and ${ }^{235} \mathrm{U}(\mathrm{n}, \mathrm{x})$ respectively. For the test experiment, the exit channel sought was fission. The wellknown ${ }^{235} \mathrm{U}(\mathrm{n}, \mathrm{f})$ cross section acts as a reference for the unknown ${ }^{240} \mathrm{Am}(\mathrm{n}, \mathrm{f})$. In a full experiment with good statistics the $t-f$ coincidence spectra are divided by one another and multiplied by the known cross section of interest. For example the ${ }^{240} \mathrm{Am}(\mathrm{n}, \mathrm{f})$ cross section would be determined by

$$
\sigma_{240}(n, f)(E)=\frac{N_{t-f}\left({ }^{243} A m(p, t f), E\right)}{N_{t-f}\left({ }^{238} U(p, t f), E\right)} \times \frac{\sigma_{C N,{ }^{244} A m}(E)}{\sigma_{C N,{ }^{236} U}(E)} \times \sigma_{{ }^{235} U}(n, f)(E),
$$

where $\mathrm{N}_{\mathrm{t}-\mathrm{f}}\left({ }^{243} \mathrm{Am}(\mathrm{p}, \mathrm{t}), \mathrm{E}\right)$ and $\mathrm{N}_{\mathrm{p}-\mathrm{f}}\left({ }^{238} \mathrm{U}(\mathrm{p}, \mathrm{t}), \mathrm{E}\right)$ are the number of ${ }^{243} \mathrm{Am}$ and ${ }^{238} \mathrm{U}$ particle-fission coincidence events (corrected for experimental conditions) at a given energy, $\sigma_{\mathrm{CN}}(\mathrm{E})$ are the compound nuclear formation cross sections using the neutron-induced reactions, and $\sigma^{235} \mathrm{U}(\mathrm{n}, \mathrm{f})(\mathrm{E})$ is the known energy dependent ${ }^{235} \mathrm{U}$ cross section.

For the test experiment, enough data was collected during the 48 hour run to determine expected triton-fission coincidence rates for each reaction. A measurement of the cross-section was beyond the scope of the effort at this time.

\section{Targets}

For this experiment, a ${ }^{243} \mathrm{Am}$ target $\left(115 \mathrm{ug} / \mathrm{cm}^{2}\right)$ prepared earlier in FY11 was used. The ${ }^{238} \mathrm{U}$ target $\left(761 \mathrm{ug} / \mathrm{cm}^{2}\right)$ from an earlier effort was also used.

\section{Results}

The beam energy was initially chosen to be $39 \mathrm{MeV}$ in order to measure an equivalent neutron energy range from 0 to $20 \mathrm{MeV}$. However, the proton beam was not stopped in the farady cup and the beam was deposited in the surrounding shielding material. The shielding material was not conductive, and a beam current, needed for proper tuning of the beam as well as experimental monitoring, could not be read. If the ${ }^{240} \mathrm{Am}(\mathrm{n}, \mathrm{f})$ surrogate experiment is to be run at $\mathrm{LBNL}$, simple modifications to the beam collection site will need to be made. 
The beam energy was reduced to $29 \mathrm{MeV}$, which was within an energy regime of prior experiments and tuning conditions at STARS/LIBERACE. At this energy, the beam current was successfully tuned and measured. At $29 \mathrm{MeV}$, data was collected with both the ${ }^{243} \mathrm{Am}$ and ${ }^{238} \mathrm{U}$ targets. An example particle identification plot is shown in Fig. 1.

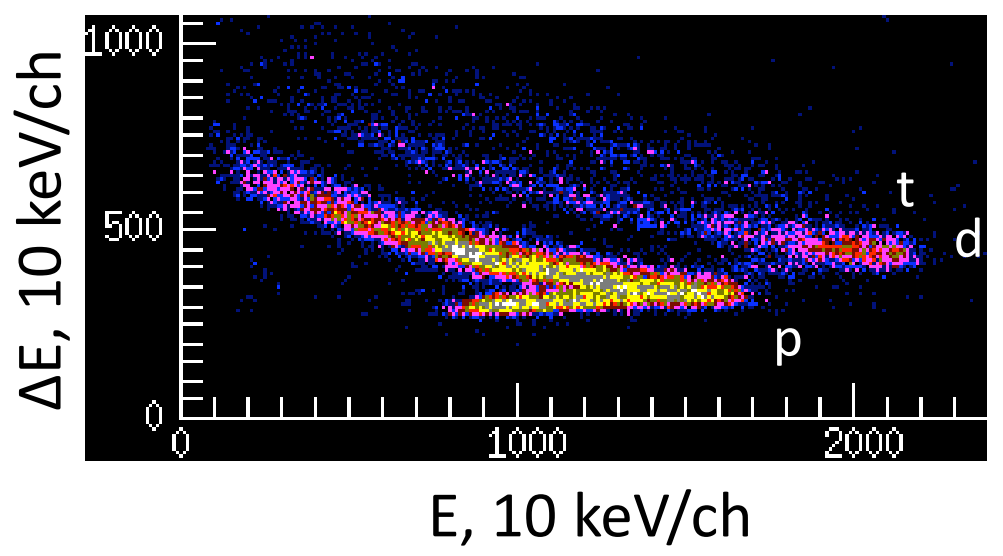

Figure 1. Particle identification for 29-MeV protons incident on a ${ }^{238} \mathrm{U}$ target; outgoing particles $(p, d, t)$ coincident with fission events is shown.

The triton-fission coincidence rate for the ${ }^{243} \mathrm{Am}$ target and ${ }^{238} \mathrm{U}$ target were measured. Coincidence rates of 0.0233(1) cps and 0.150(6) cps were observed for the ${ }^{243} \mathrm{Am}$ and ${ }^{238} \mathrm{U}$ targets, respectively. The difference in count rate is largely attributed to the available target material - the ${ }^{238} \mathrm{U}$ target contains approximately 7 times more atoms than the ${ }^{243} \mathrm{Am}$.

A proton beam current of $\sim 0.7 \mathrm{nA}$ was used for measurements on both targets. Assuming a full experimental run under similar conditions, an estimate for the run time needed was made. Figure 2 shows the number of days needed as a function of acceptable uncertainty for a measurement of $1-20 \mathrm{MeV}$ equivalent neutron energy, binned into $200 \mathrm{keV}$ increments.

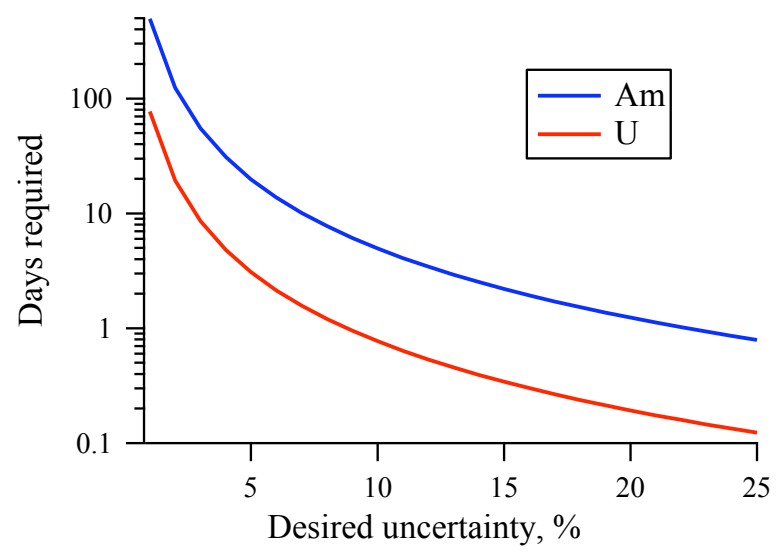

Figure 2. Measurement days needed as a function of uncertainty for the ${ }^{240} \mathrm{Am}(n, f)$ and ${ }^{235} U(n, f)$ using the $(p, t)$ surrogate reactions with conditions similar to the test experiment. 
A 5\% measurement will take 3 days for $\mathrm{U}$, but 20 days for Am. It may be difficult to be the sole user of the LBNL cyclotron, or another facility, for such an extended period. However, a 10\% measurement will take 19 hours for U, and 5 days for Am. Such a run period is more reasonable and will allow for the first ever measurement of the ${ }^{240} \mathrm{Am}(\mathrm{n}, \mathrm{f})$ cross section.

We also anticipate $40 \%$ more beam time being available at Texas A\&M Cyclotron Institute compared to LBNL in FY2012. The increased amount of beam time will allow us to accumulate better statistics then what would have been available at LBNL.

\section{Collaborators}

For this experiment, we collaborated with the University of Tennessee, the University of California Berkeley and Lawrence Berkeley National Laboratory.

\section{Acknowledgements}

We wish to acknowledge the efforts of the 88 Inch Cyclotron Staff who ensured the success of this experimental effort. This work performed under the auspices of the U.S. Department of Energy by Lawrence Livermore National Laboratory under Contract DE-AC52-07NA27344 and the Department of Energy's NNSA, Office of Nonproliferation Research and Development (NA-22). 